\title{
Butein inhibits the proliferation of breast cancer cells through generation of reactive oxygen species and modulation of ERK and p38 activities
}

\author{
LI-HENG YANG ${ }^{1,2}$, YING-JUI HO ${ }^{3}$, JING-FENG LIN ${ }^{4}$, CHI-WEI YEH ${ }^{4}$, SHAO-HSUAN KAO ${ }^{4}$ and LI-SUNG HSU ${ }^{4,5}$ \\ ${ }^{1}$ Department of Surgery, Changhua Christian Hospital, Changhua; ${ }^{2}$ Department of Surgery, Nantou Christian Hospital, Nantou; \\ ${ }^{3}$ School of Psychology, and ${ }^{4}$ Institute of Biochemistry and Biotechnology, Chung Shan Medical University; \\ ${ }^{5}$ Clinical Laboratory, Chung Shan Medical University Hospital, Taichung, Taiwan, R.O.C.
}

Received May 3, 2012; Accepted June 14, 2012

DOI: $10.3892 / \mathrm{mmr} .2012 .1023$

\begin{abstract}
Butein (3,4,2',4'-tetrahydroxychalcone) is a polyphenol derived from various natural plants and is capable of inducing several types of death in cancer cells. However, the molecular mechanisms underlying butein-induced breast cancer cell apoptosis remain unknown. The present study aimed to prove that butein inhibits the proliferation of MDA-MB-231 human breast cancer cells in a dose- and time-dependent manner. Butein markedly induced the generation of reactive oxygen species (ROS), decreased the phosphorylation of extracellular signal-regulated kinase (ERK), increased p38 activity, diminished Bcl-2 expression, induced caspase 3 cleavage and was associated with poly(ADP-ribose) polymerase (PARP) cleavage. Our findings also indicate that ROS may play an important role in butein-induced apoptosis, as pre-treatment with the antioxidant, $\mathrm{N}$-acetyl cysteine (NAC), prevented butein-induced apoptosis. In conclusion, our results demonstrate that butein inhibits the proliferation of breast cancer cells through the generation of ROS and the modulation of ERK and p38 activities. We also demonstrate that these effects may be abrogaged by pre-treatment with NAC. Our results suggest that butein may function as a potential therapeutic agent for the treatment of breast cancer.
\end{abstract}

\section{Introduction}

Extracts from certain dietary foods or medical plants may function as chemopreventive agents and may inhibit tumorigenesis, including the initiation and promotion of several types of human cancer $(1,2)$. Butein $(3,4,2$ ',4'-tetrahydroxychalcone)

Correspondence to: Professor Li-Sung Hsu, Institute of Biochemistry and Biotechnology, Chung Shan Medical University, No. 110, Sec.1, Jianguo N. Rd., Taichung 402, Taiwan, R.O.C.

E-mail: 1shsu405@yahoo.com.tw

Key words: apoptosis, breast cancer, butein, extracellular signalregulated kinase, p38, reactive oxygen species is a bioactive polyphenol that is isolated from a number of plants, including Semecarpus anacardium, Dalbergia odorifera and Rhus verniciflua Stokes (R. verniciflua) (3). In Korea, butein is used as a food additive (3). Butein has been shown to demonstrate multiple biological functions, including anti-inflammatory, antioxidative and antimicrobial functions $(4,5)$. Butein abolishes the effects of lipopolysaccharideinduced inflammation through the inhibition of nuclear factor $\kappa \mathrm{B}(\mathrm{NF} \kappa \mathrm{B})$ activities and c-jun $\mathrm{N}$-terminal kinase (JNK)-dependent pathways (5). Butein has also been shown to exert free radical scavenging activities and suppress $\mathrm{H}_{2} \mathrm{O}_{2}$-induced cytotoxicity in RAW264.7 macrophage cell lines (4). Additionally, butein decreases phorbol ester-induced skin cancer formation (6), ameliorates renal concentration capacity in cisplatin-induced renal failure (7), attenuates diabetic complications (8) and facilitates recovery in carbon tetrachloride-induced liver fibrosis (9).

Previous reports have focused on the anti-proliferative and anti-metastatic effects of butein. Jang et al showed that flavonoids isolated from $R$. verniciflua inhibited proliferation and triggered apoptosis in human osteosarcoma cells (10). These compounds, including butein, enhance p53 and Bax expression, decrease Bcl2 levels and subsequently induce apoptosis in osteosarcoma cells (11). Butein inhibits the colony formation of UACC-812 human breast cancer cells when it is co-cultured with fibroblast cells (11). Butein-treated colon adenocarcinoma and HeLa cells showed a significant reduction in cell proliferation $(12,13)$. Iwashita et al showed that butein also triggered melanoma cells to undergo apoptosis, as evidenced by DNA condensation, DNA fragmentation and an increased frequency of hypodiploid cells; the authors also demonstrated that increased Bax and decreased Bcl-xL levels contribute to this butein-induced apoptosis (14). The treatment of U937 human leukemia cells with sublethal concentrations of butein has been shown to sensitize the cells to tumor necrosis factor(TNF)-related apoptosis-inducing ligand (TRAIL)-induced apoptosis through increasing caspase 3-dependent pathways (14). Moreover, butein suppresses the signal transduction and activation of transcription 3 (STAT3) activity and reduces STAT3 target gene expression in multiple myeloma cells and human hepatocarcinoma cells $(15,16)$. Treatment with butein 
was shown to induce $\mathrm{G}_{2} / \mathrm{M}$ arrest, by enhancing ataxia telangiectasia mutated (ATM), Chk1 and Chk2 activities in hepatoma cells (15). Butein has also been found to inhibit the invasion and angiogenesis of prostate cancer through the downregulation of matrix metalloproteinase (MMP)-9 and vascular endothelial growth factor expression (17).

Due to the high prevalence and increasing drug resistance of breast cancer, this disease has become the leading cause of cancer-related mortality in women. Studies focusing on natural compounds for the treatment of breast cancer have begun to emerge (18). A polyphenol-rich fraction purified from $R$. verniciflua containing fesetin, sulfuretin and butein, has demonstrated anti-proliferative effects both in gastric and breast cancer (19). Butein also diminishes the testosteroneinduced cell proliferation of breast cancer cells by reducing aromatase activity (19). Chua et al demonstrated that butein suppresses the migration and invasion of breast cancer through the inhibition of NFKB activity and subsequent decrease in CXC chemokine receptor 4 (CXCR4) expression (20). Recently, butein has been shown to block phorbol 12-myristate 13-acetate (PMA)-elevated cyclooxygenase 2 (COX2) expression by inhibiting extracellular signal-regulated kinase (ERK) activation in cancerous and non-cancerous breast cells (21). However, the effects of butein on the growth and proliferation of breast cancer cells remain unclear. In this study, the molecular mechanisms of the effects of butein on breast cancer cell proliferation are delineated for the first time.

\section{Materials and methods}

Materials. All chemicals that were used, including butein, isopropanol, dimethylsulfoxide (DMSO) and propidium iodine, were purchased from Sigma Chemical Company (St. Louis, MA, USA). The phospho-p38 antibody was purchased from Cell Signaling Technology (Beverly, MA, USA). Antibodies against p38, phospho-ERK and ERK were obtained from Santa Cruz Biotechnology (Santa Cruz, CA, USA). Anti- $\beta$ actin and horseradish peroxidase (HRP)-conjugated secondary antibodies were obtained from Sigma Chemical Company. Dulbecco's modified Eagle's medium (DMEM), fetal bovine serum and penicillin-streptomycin mixture were obtained from Gibco Laboratory (Gaithersburg, MO, USA).

Cell culture. The human breast cancer cell line MDA-MB231 was maintained in DMEM supplemented with $10 \%$ fetal bovine serum, 100 units $/ \mathrm{ml}$ penicillin and $100 \mu \mathrm{g} / \mathrm{ml}$ streptomycin at $37^{\circ} \mathrm{C}$ in a humidified atmosphere of $5 \% \mathrm{CO}_{2}$.

3-(4,5 Dimethylthiazol-2-yl)-2,5 diphenyltetrazolium bromide (MTT) assay. Cells were seeded in 24-well plates at a density of $4 \times 10^{4}$ cells $/ \mathrm{ml}$ and were treated with the indicated concentrations of butein for 24 or $48 \mathrm{~h}$. After removing the supernatant, the cells were incubated with fresh medium containing $5.0 \mathrm{mg} / \mathrm{l} \mathrm{MTT}$ at $37^{\circ} \mathrm{C}$ for an additional $3 \mathrm{~h}$. After washing with phosphate-buffered saline (PBS), the purpleblue formazan was dissolved in $1 \mathrm{ml}$ of isopropanol, and the absorbance was measured at $563 \mathrm{~nm}$.

Reactive oxygen species (ROS) analysis. Cells treated with the indicated concentrations of butein, with or without pre-treatment with $1 \mathrm{mM} \mathrm{N}$-acetyl cysteine (NAC) for $1 \mathrm{~h}$, were loaded with $5 \mu \mathrm{M}$ fluorescent probe 2',7'-dichlorodihydrofluorescein diacetate (H2DCFDA; Molecular Probes Inc., Eugene, OR, USA) at $37^{\circ} \mathrm{C}$ for $1 \mathrm{~h}$. The fluorescence intensity was analyzed on BD biosciences FACscan system using CellQuest ${ }^{\mathrm{TM}}$ Pro software.

Western blot analysis. MDA-MB-231 cells were treated with the indicated concentrations of butein for $48 \mathrm{~h}$ and then cell lysate extraction was performed. Protein concentration was detected by using a Bradford protein assay kit (Bio-Rad Laboratories, Hercules, CA, USA). Protein $(20 \mu \mathrm{g})$ was separated by a $10 \%$ polyacrylamide gel and electrotransferred to a nitrocellulose membrane. The membrane was blocked by PBS containing $0.5 \%$ non-fat milk for $1 \mathrm{~h}$ at room temperature. After being washed with PBS containing 0.1\% Tween-20 (PBST), the membrane was probed with primary antibodies at $4^{\circ} \mathrm{C}$ overnight. The following day, the membrane was washed with PBST and then incubated with HRP-conjugated goat anti-mouse IgG antibody (Santa Cruz Biotechnology; 1:5,000 dilution) at room temperature for $1 \mathrm{~h}$. The membrane was extensively washed with PBS, and the reactive signal was detected using an enhanced chemiluminescence kit (Amersham Pharmacia Biotech, UK). $\beta$-actin expression was used as the loading control.

Statistical analysis. Reported data are the means \pm standard deviation (SD) of 3 independent experiments and were evaluated by the Student's t-test with SPSS. A p-value $<0.05$ was considered to indicate a statistically significant difference.

\section{Results}

Butein inhibits cell proliferation in breast cancer cells. Previous reports have shown that butein is a potent antiproliferative agent for several types of cancer. The present study investigated the cytotoxic effects of butein on the breast cancer cell line, MDA-MB-231. Low doses $(6.25$ and $12.5 \mu \mathrm{M})$ of butein did not affect cell viability, whereas treatment with 25,50 and $100 \mu \mathrm{M}$ butein reduced cell viability to 88,73 and $61 \%$ after $24 \mathrm{~h}$ and to 66,49 and $26 \%$ after $48 \mathrm{~h}$, respectively (Fig. 1). In addition, a significantly increased sub- $\mathrm{G}_{1}$ population was found in the 50 and $100 \mu \mathrm{M}$ butein-treated groups (Table I). Taken together, our results suggest that butein induces apoptosis in breast cancer cells.

Butein modulates ERK and p38 activity in breast cancer cells. In general, ERK is involved in cell proliferation, whereas JNK and p38 participate in stress-induced apoptosis (22). To detect whether MAPK family proteins are involved in butein-induced apoptosis, the phosphorylation of ERK and p38 was measured by western blot analysis. As shown in Fig. 2A, ERK phosphorylation was significantly decreased in the butein-treated cells $(90 \%$ at $6.25 \mu \mathrm{M}, 80 \%$ at $12.5 \mu \mathrm{M}, 75 \%$ at $25 \mu \mathrm{M}, 61 \%$ at $50 \mu \mathrm{M}$ and $45 \%$ at $100 \mu \mathrm{M}$, compared with $100 \%$ in the control group). By contrast, $100 \mu \mathrm{M}$ butein increased the phosphorylation of p38 up to 1.59-fold compared with the vehicle-treated group (Fig. 2B). No overt alteration in JNK phosphorylation was observed in the presence of butein (data not shown).

Effects of butein on apoptosis-related protein expression. In order to determine whether butein affects apoptosis-related 
Table I. Cell cycle distribution of butein- and/or NAC-treated MDA-MB-231 cells.

\begin{tabular}{lccrr}
\hline Treatment group & Sub- $\mathrm{G}_{1}(\%)$ & $\mathrm{G}_{0} / \mathrm{G}_{1}(\%)$ & $\mathrm{S}(\%)$ & $\mathrm{G}_{2} / \mathrm{M}^{(\%)}$ \\
\hline Control & $0.38 \pm 0.12$ & $48.93 \pm 3.75$ & $9.43 \pm 0.73$ & $30.59 \pm 7.79$ \\
Butein $6.25 \mu \mathrm{M}$ & $0.35 \pm 0.1$ & $47.93 \pm 5.38$ & $9.57 \pm 1.68$ & $32.47 \pm 5.69$ \\
Butein $12.5 \mu \mathrm{M}$ & $0.39 \pm 0.2$ & $49.42 \pm 7.84$ & $9.32 \pm 1.13$ & $30.39 \pm 6.73$ \\
Butein $25 \mu \mathrm{M}$ & $0.67 \pm 0.37$ & $47.33 \pm 8.78$ & $9.54 \pm 1.58$ & $44.08 \pm 7.04$ \\
Butein $50 \mu \mathrm{M}$ & $3.71 \pm 0.6^{\mathrm{a}}$ & $45.69 \pm 6.08$ & $16.26 \pm 1.77$ & $24.73 \pm 1.69$ \\
Butein $100 \mu \mathrm{M}$ & $11.22 \pm 2.62^{\mathrm{a}}$ & $50.42 \pm 11.44$ & $8.53 \pm 4.19$ & $24.01 \pm 2.71$ \\
NAC alone & $0.51 \pm 0.34$ & $57.82 \pm 7.45$ & $9.56 \pm 1.23$ & $16.64 \pm 4.39$ \\
Butien $50 \mu \mathrm{M}+$ NAC & $1.57 \pm 0.33^{\mathrm{b}}$ & $51.77 \pm 8.82$ & $11.43 \pm 1.81$ & $24.16 \pm 1.98$ \\
Butien $100 \mu \mathrm{M}+$ NAC & $3.61 \pm 0.79^{\mathrm{b}}$ & $52.09 \pm 4.82$ & $11.63 \pm 3.37$ & $24.01 \pm 2.71$ \\
\hline
\end{tabular}

${ }^{\mathrm{a}} \mathrm{p}<0.05$ compared to control group; ${ }^{\mathrm{b}} \mathrm{p}<0.05$ compared to 50 and $100 \mu \mathrm{M}$ butein group. NAC, $\mathrm{N}$-acetyl cysteine.

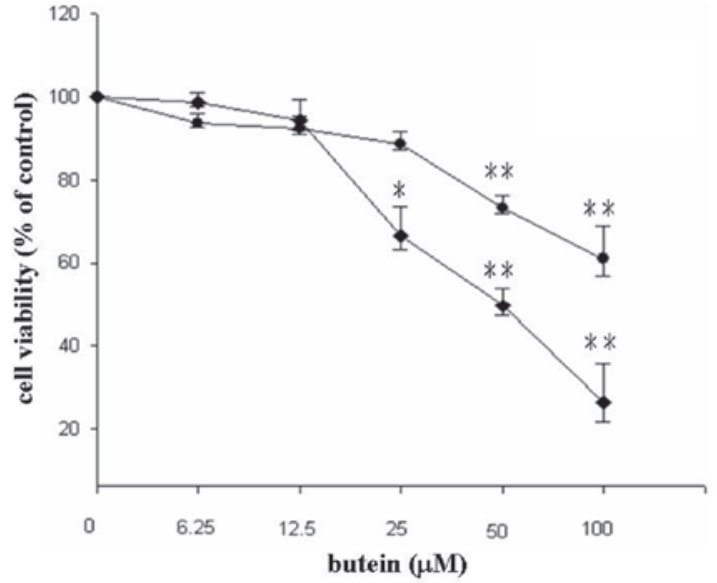

Figure 1. Effects of butein on the cell viability of breast cancer cells. MDAMB-231 human breast cancer cells were treated with the indicated concentrations of butein for 24 (closed circle) and $48 \mathrm{~h}$ (diamond). Cell viability was measured by MTT assay. Data presented are the means \pm SD from at least 3 independent experiments. ${ }^{*} \mathrm{p}<0.05,{ }^{* *} \mathrm{p}<0.01$ compared with the vehicle-treated group.

(A)

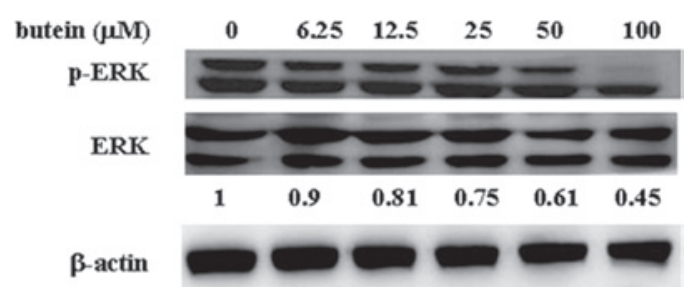

(B)

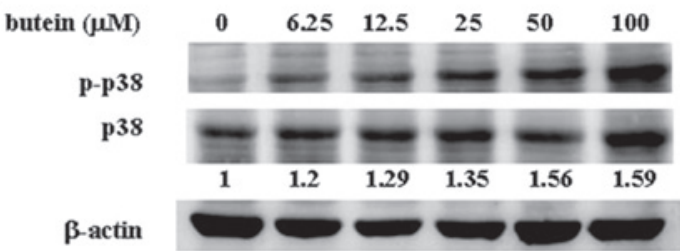

Figure 2. Effects of butein on extracellular signal-regulated kinase (ERK) and p38 phosphorylation. MDA-MB-231 cells were treated with the indicated concentrations of butein for $48 \mathrm{~h}$. Cell lysates were harvested and subjected to western blot analysis using (A) phospho-ERK and ERK and (B) phospho-p38 and p38 antibodies. Data represent 1 of at least 3 independent experiments. $\beta$-actin was used as the internal control.

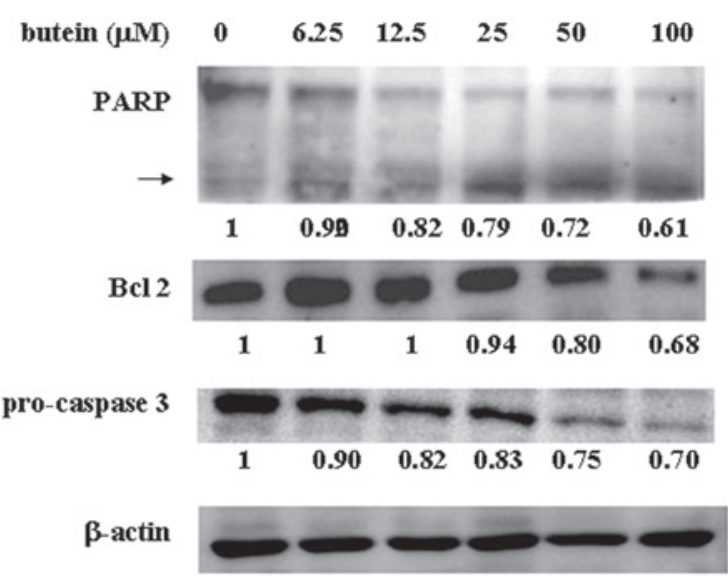

Figure 3. Effects of butein on apoptosis-related protein expression. Cell lysates derived from butein-treated MDA-MB-231 cells were subjected to western blot analysis. The expressions of poly(ADP-ribose) polymerase (PARP), Bcl-2 and caspase 3 were measured. Arrow indicates the cleaved form of PARP. $\beta$-actin was used as the internal control.

protein expression, cell lysates derived from butein-treated MB-MDA-231 cells were harvested, and the expression of $\mathrm{Bcl}-2$, caspase 3 and poly-(ADP-ribose)-polymerase (PARP) were analyzed by western blot analysis. The expression of the anti-apoptotic protein, Bcl-2, was dramatically decreased in a dose-dependent manner based on the butein concentration. In addition, butein also reduced pro-caspase 3 expression and increased cleavage of PARP in a dose-dependent manner (Fig. 3). However, no significant alteration in Bax expression was found in the presence of butein (data not shown).

Butein triggers ROS generation. To examine whether butein triggers ROS production, butein-treated MB-MDA-231 cells were stained with 2'-7'-dichlorofluorescin diacetate fluorescent dye and were analyzed by flow cytometry. As shown in Fig. 4A, treatment with 50 and $100 \mu \mathrm{M}$ butein significantly increased ROS generation. Pre-treatment with NAC significantly decreased ROS production.

Pre-treatment with the antioxidant agent, NAC, prevents butein-induced protein expression and cell death. To determine whether the butein-induced apoptosis is mediated by 
(A)
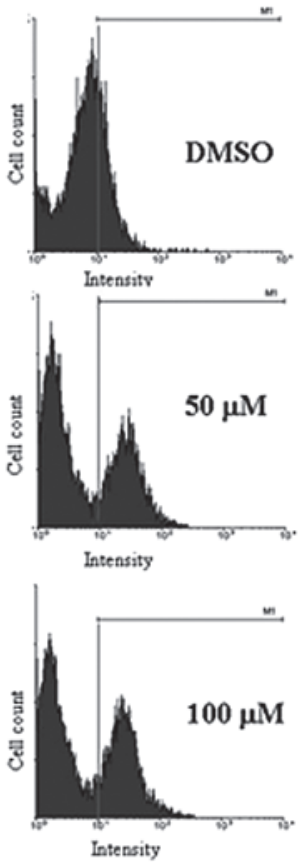
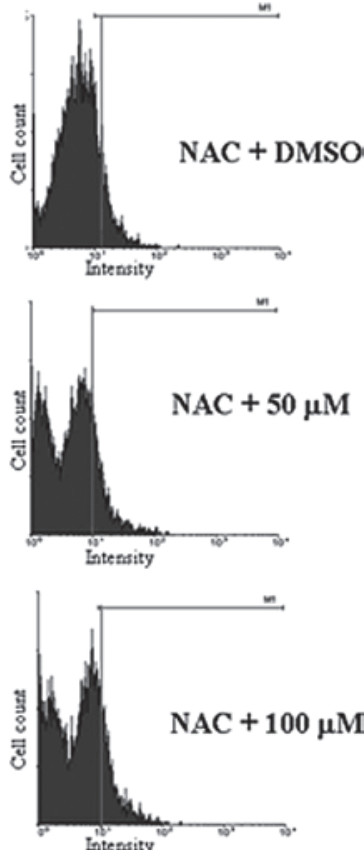

(B)

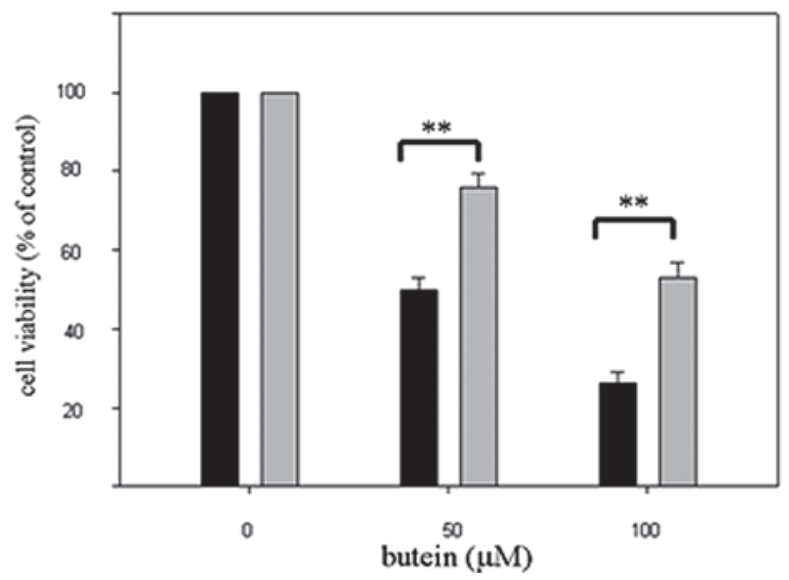

Figure 4. Pre-treatment with $\mathrm{N}$-acetyl cysteine (NAC) reverses the effects of butein on: (A) reactive oxygen species (ROS) generation and (B) cell viability. MDA-MB-231 cells were pre-treated with $1 \mathrm{mM}$ NAC and then treated with 50 or $100 \mu \mathrm{M}$ butein for an additional $48 \mathrm{~h}$. Cells were stained with DCFDA and ROS was analyzed by flow cytometry. X and Y axis denote the DCFDA intensity and cell count, respectively. Line indicates the $10^{2}$ intensity. (B) Cells were treated as mentioned above and the cell viability was measured by MTT assay. Data are the means \pm SD from at least 3 independent experiments. Black bar indicates treatment with butein alone. Gray bar indicates combined treatment of butein and NAC. ${ }^{* *}$ p $<0.01$ compared with the group treated with butein alone.

ROS generation, the cells were pre-treated with $1 \mathrm{mM}$ NAC and were subsequently co-treated with the indicated concentrations of butein for an additional $48 \mathrm{~h}$. Cell viability was measured by MTT assay, and the apoptotic population was detected by flow cytometry. Pre-treatment with NAC markedly increased the viability of butein-treated cells as shown by MTT assays (Fig. 4B). Similarly, NAC pre-treatment decreased the sub-G1 population from 3.71-1.57 and $11.22-3.61 \%$, in response to 50 and $100 \mu \mathrm{M}$ butein treatment, respectively (Table I). Moreover, to address whether the effects of butein on apoptosis-related protein expression are affected by the abrogation of ROS generation, the phosphorylation of ERK and p38 was measured in NAC-pre-treated cells. Notably, as shown in Fig. 5, pre-treatment with NAC significantly blocked the butein-induced phosphorylation of p38. In addition, ERK phosphorylation was upregulated in the presence of NAC.
Our findings suggest that the generation of ROS, which may modulate ERK and p38 activities, plays an important role in butein-induced apoptosis.

\section{Discussion}

Flavonoids, which are compounds found in fruits and vegetables, have received a great deal of attention for their application as chemopreventive and chemotherapeutic agents $(23,24)$. Butein, one of the major constituents of $R$. verniciflua, has been shown to exert a wide range of biological functions. Butein has been demonstrated to inhibit the proliferation of several human cancer cell lines, including B16 melanoma 4A5 cells (14), lymphoma (3), breast carcinoma (19) and osteosarcoma cells (10). In this study, the molecular mechanisms underlying the role of butein in the cell proliferation of breast cancer cells 


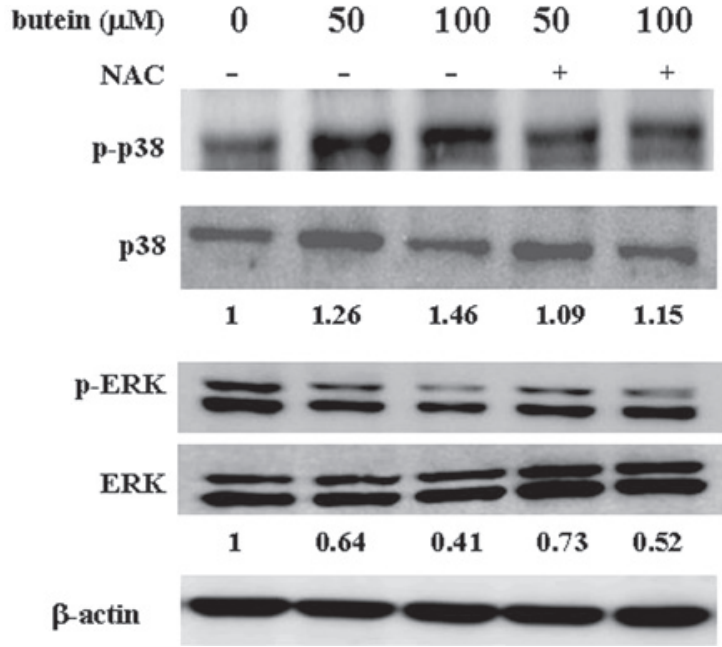

Figure 5. Effects of N-acetyl cysteine (NAC) on phosphorylation of (ERK) and $\mathrm{p} 38$ in the presence of butein. MDA-MB-231 cells were pre-treated with $1 \mathrm{mM}$ NAC and then treated with 50 or $100 \mu \mathrm{M}$ butein for an additional $48 \mathrm{~h}$. Cell lysates were collected and subjected to western blot analysis using the indicated antibodies. p-ERK/ERK ratio and p-p38/p38 ratios were calculated and compared to the vehicle-treated group. The data represent 1 of 3 independent experiments.

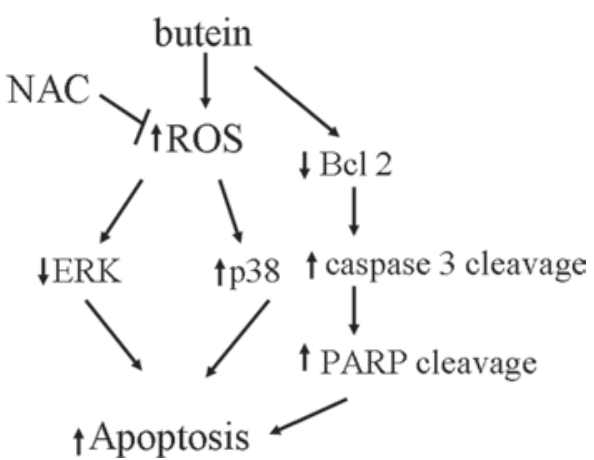

Figure 6. Summarization of the molecular mechanisms of butein on the inhibition of cell proliferation of breast cancer cells. Treatment with butein induced reactive oxygen species (ROS) generation, inhibited extracellular signal-regulated kinase (ERK) activity, enhanced p38 activation, decreased Bcl-2 expression, triggered the cleavage of pro-caspase 3 and poly(ADPribose) polymerase (PARP) and consequently inhibited cell proliferation in breast cancer cells. Pre-treatment with $\mathrm{N}$-acetyl cysteine (NAC) significantly blocked these butein-induced effects

were delineated for the first time. Our data demonstrate that butein reduces cell viability in a dose- and time-dependent manner. Butein induced cell apoptosis, as evidenced by an increase in the sub- $\mathrm{G}_{1}$ cell population. Treatment with butein elevated ROS generation, enhanced the proteolytic activity of caspase 3, decreased the expression of Bcl-2 protein, decreased the phosphorylation of ERK and stimulated p38 phosphorylation. Pre-treatment with the antioxidant, NAC, significantly abrogated butein-induced apoptosis.

Mitogen-activated protein kinase (MAPK) family proteins have been shown to regulate numerous cellular functions, such as cell proliferation, cell growth and apoptosis, in response to different extracellular stimuli $(22,25)$. In general, ERK-mediated growth factors enhance cell proliferation, whereas JNK and p38 kinases transduce signals from stress and inflammation to promote apoptosis (26). Flavonoid-triggered cancer cells undergo apoptosis through the modulation of MAPK protein kinases (27-29). Epigallocatechin-3-gallate (EGCG) inhibits ERK activation and increases p38 kinases and JNK activity, which subsequently enhances apoptosis in pancreatic cancer cells (30). Treatment with quercetin significantly reduces the phosphorylation of ERK and AKT, which is accompanied by decreased cell viability in glioma and HepG2 cells $(31,32)$. In bladder cancer cells, treatment with butein decreases the phosphorylation of ERK in a time-dependent manner (33). Lau et al showed that butein attenuated COX2 expression induced by PMA, via the inhibition of ERK activities (21). In our study, treatment with butein significantly abrogated ERK activities in MDA-MB-231 breast cancer cells, consistent with previous observations. Unlike other flavonoids that induce p38 activation, Lee et al showed that treatment with butein significantly diminished TNF- $\alpha$-mediated MMP-7 and interleukin 8 production by decreasing p38 activity in HT-29 cells (34). However, our findings provide the first evidence that treatment with butein significantly elevates p38 activity in a dose-dependent manner. Taken together, our results indicate that treatment with butein attenuates survival signals (ERK) and elevates death signals (p38), which leads to apoptosis in breast cancer cells.

The Bcl-2 family proteins have both anti- and pro-apoptotic functions. The ratio of pro-apoptotic (Bax) to anti-apoptotic (Bcl-2) proteins determines whether a cell lives or dies. An increased $\mathrm{Bax} / \mathrm{Bcl}-2$ ratio triggers apoptosis by releasing cytochrome $\mathrm{c}$ from mitochondria, which in turn activates caspase 3 (35). As proof of principle, butein induces apoptosis in HL60 leukemia cells through diminished Bcl-2 and elevated Bax expression, which results in stimulated caspase 3 activity (36). Similarly, crude extracts of $R$. verniciflua, rich in butein, fustin and fisetin have demonstrated apoptotic effects on human osteosarcoma cells through the inhibition of Bcl-2 expression and the activation of Bax expression (10). In the present study, decreased Bcl-2 and pro-caspase 3 levels, accompanied by increased PARP cleavage, were found in butein-treated breast cancer cells.

The production of ROS, which damages DNA, proteins and lipids, has been associated with a number of human diseases, such as atherosclerosis and cancer $(37,38)$. Increased ROS concentrations help facilitate the chemotherapeutic effects of flavonoids. Apigenin triggers prostate cancer cells to undergo apoptosis through the generation of ROS and the activation of the p53 pathway (40). Similarly, kaempferol and catechins also induce apoptosis in glioblastoma and malignant B cells, respectively, via the production of ROS $(40,41)$. Emerging reports have demonstrated that elevated ROS levels trigger signal transduction pathways involved in apoptosis. In hepatoma cells, butein triggers ROS generation, modulates ATM, Chk1 and Chk2 activities, and subsequently causes cell cycle arrest in the $G_{2} / M$ phase (42). Very recently, it has also been shown that butein elevates ROS levels and subsequently triggers apoptosis in neuroblastoma cells (43). Pre-treatment with antioxidants, such as NAC or glutathione, abrogates the effects of butein (41). In our study, concurrent with a previous report, treatment with 50 and $100 \mu \mathrm{M}$ butein markedly induced ROS generation in MDA-MB-231 breast cancer cells. Pre-treatment with the antioxidant, NAC, counteracted the effects of butein on cell viability and ROS generation. However, $\mathrm{G}_{2} / \mathrm{M}$ phase 
arrest was not observed in butein-treated breast cancer cells Our data reveal that butein triggers apoptosis, but not cell cycle arrest in breast cancer cells, via the generation of ROS.

In conclusion, our results, to our knowledge, provide the first evidence that butein triggers apoptosis in breast cancer cells via multiple mechanisms and the generation of ROS, inhibition of ERK, activation of p38, decreased Bcl-2 expression levels and induced cleavage of caspase 3 and PARP, whereas pre-treatment with the antioxidant, NAC, prevents these butein-induced effects (Fig. 6). In conclusion, our results suggest that butein has anti-proliferative effects and induces apoptosis in breast cancer cells.

\section{Acknowledgements}

The present study was supported by grants from the National Science Council of Taiwan (NSC-94-2311-B-040-002 and NSC-93-2311-B-040-009) and from the Chung Shan Medical University (98-CCH-CSMU-05). The authors thank the Instrument Center of the Chung Shan Medical University, supported by the National Science Council of the Ministry of Education and the Chung Shan Medical University for providing the equipment.

\section{References}

1. Kelloff GJ, Boone CW, Crowell JA, Steele VE, Lubet R and Sigman CC: Chemopreventive drug development: perspectives and progress. Cancer Epidemiol Biomarkers Prev 3: 85-98, 1994

2. Khan N, Afaq F and Mukhtar H: Cancer chemoprevention through dietary antioxidants: progress and promise. Antioxid Redox Signal 10: 475-510, 2008.

3. Lee JC, Lee KY, Kim J, Na CS, et al: Extract from Rhus verniciflua Stokes is capable of inhibiting the growth of human lymphoma cells. Food Chem Toxicol 42: 1383-1388, 2004.

4. Jung CH, Jun CY, Lee S, Park CH, Cho K and Ko SG: Rhus verniciflua stokes extract: radical scavenging activities and protective effects on $\mathrm{H}_{2} \mathrm{O}_{2}$-induced cytotoxicity in macrophage RAW 264.7 cell lines. Biol Pharm Bull 29: 1603-1607, 2006.

5. Jung $\mathrm{CH}$, Kim JH, Hong MH, et al: Phenolic-rich fraction from Rhus verniciflua Stokes (RVS) suppress inflammatory response via NF-kappaB and JNK pathway in lipopolysaccharide-induced RAW 264.7 macrophages. J Ethnopharmacol 110: 490-497, 2007

6. Aizu E, Nakadate T, Yamamoto S and Kato R: Inhibition of 12-O-tetradecanoylphorbol-13-acetate-mediated epidermal ornithine decarboxylase induction and skin tumor promotion by new lipoxygenase inhibitors lacking protein kinase $\mathrm{C}$ inhibitory effects. Carcinogenesis 7: 1809-1812, 1986.

7. Kang DG, Lee AS, Mun YJ, et al: Butein ameliorates renal concentrating ability in cisplatin-induced acute renal failure in rats. Biol Pharm Bull 27: 366-370, 2004.

8. Lim SS, Jung SH, Ji J, Shin KH and Keum SR: Synthesis of flavonoids and their effects on aldose reductase and sorbitol accumulation in streptozotocin-induced diabetic rat tissues. J Pharm Pharmacol 53: 653-668, 2001.

9. Lee SH, Nan JX, Zhao YZ, et al: The chalcone butein from Rhus verniciflua shows antifibrogenic activity. Planta Med 69: 990-994, 2003

10. Jang HS, Kook SH, Son YO, et al: Flavonoids purified from Rhus verniciflua Stokes actively inhibit cell growth and induce apoptosis in human osteosarcoma cells. Biochim Biophys Acta 1726: 309-316, 2005.

11. Kook SH, Son YO, Chung SW, et al: Caspase-independent death of human osteosarcoma cells by flavonoids is driven by p53-mediated mitochondrial stress and nuclear translocation of AIF and endonuclease G. Apoptosis 12: 1289-1298, 2007.

12. Ramanathan R, Tan CH and Das NP: Cytotoxic effect of plant polyphenols and fat-soluble vitamins on malignant human cultured cells. Cancer Lett 62: 217-224, 1992

13. Yit CC and Das NP: Cytotoxic effect of butein on human colon adenocarcinoma cell proliferation. Cancer Lett 82: 65-72, 1994.
14. Iwashita K, Kobori M, Yamaki K and Tsushida T: Flavonoids inhibit cell growth and induce apoptosis in B16 melanoma 4A5 cells. Biosci Biotechnol Biochem 64: 1813-1820, 2000.

15. Pandey MK, Sung B, Ahn KS and Aggarwal BB: Butein suppresses constitutive and inducible signal transducer and activator of transcription (STAT) 3 activation and STAT3regulated gene products through the induction of a protein tyrosine phosphatase SHP-1. Mol Pharmacol 75: 525-533, 2009.

16. Rajendran P, Ong TH, Chen L, et al: Suppression of signal transducer and activator of transcription 3 activation by butein inhibits growth of human hepatocellular carcinoma in vivo. Clin Cancer Res 17: 1425-1439, 2011.

17. Moon DO, Choi YH, Moon SK, Kim WJ and Kim GY: Butein suppresses the expression of nuclear factor-kappa B-mediated matrix metalloproteinase- 9 and vascular endothelial growth factor in prostate cancer cells. Toxicol In Vitro 24: 1927-1934, 2010.

18. Yang CS, Yang GY, Landau JM, Kim S and Liao J: Tea and tea polyphenols inhibit cell hyperproliferation, lung tumorigenesis, and tumor progression. Exp Lung Res 24: 629-639, 1998.

19. Kim JH, Jung CH, Jang BH, et al: Selective cytotoxic effects on human cancer cell lines of phenolic-rich ethyl-acetate fraction from Rhus verniciflua Stokes. Am J Chin Med 37: 609-620, 2009.

20. Chua AW, Hay HS, Rajendran P, et al: Butein downregulates chemokine receptor CXCR4 expression and function through suppression of NF-kappaB activation in breast and pancreatic tumor cells. Biochem Pharmacol 80: 1553-1562, 2010.

21. Lau GT, Huang H, Lin SM and Leung LK: Butein downregulates phorbol 12-myristate 13-acetate-induced COX-2 transcriptional activity in cancerous and non-cancerous breast cells. Eur J Pharmacol 648: 24-30, 2010

22. Zhang W and Liu HT: MAPK signal pathways in the regulation of cell proliferation in mammalian cells. Cell Res 12: 9-18, 2002.

23. Shankar S, Ganapathy S and Srivastava RK: Green tea polyphenols: biology and therapeutic implications in cancer. Front Biosci 12: 4881-4899, 2007.

24. Stoner GD and Mukhtar H: Polyphenols as cancer chemopreventive agents. J Cell Biochem Suppl 22: 169-180, 1995.

25. Raman M, Chen W and Cobb MH: Differential regulation and properties of MAPKs. Oncogene 26: 3100-3112, 2007.

26. Cross TG, Scheel-Toellner D, Henriquez NV, Deacon E, Salmon M and Lord JM: Serine/threonine protein kinases and apoptosis. Exp Cell Res 256: 34-41, 2000.

27. Chang IC, Huang YJ, Chiang TI, Yeh CW and Hsu LS: Shikonin induces apoptosis through reactive oxygen species/extracellular signal-regulated kinase pathway in osteosarcoma cells. Biol Pharm Bull 33: 816-824, 2010.

28. Fresco P, Borges F, Diniz C and Marques MP: New insights on the anticancer properties of dietary polyphenols. Med Res Rev 26: 747-766, 2006

29. Sarkar FH, Li Y, Wang Z and Kong D: Cellular signaling perturbation by natural products. Cell Signal 21: 1541-1547, 2009.

30. Shankar S, Suthakar G and Srivastava RK: Epigallocatechin3-gallate inhibits cell cycle and induces apoptosis in pancreatic cancer. Front Biosci 12: 5039-5051, 2007

31. Granado-Serrano AB, Martin MA, Bravo L, Goya L and Ramos S: Quercetin induces apoptosis via caspase activation, regulation of $\mathrm{Bcl}-2$, and inhibition of PI-3-kinase/Akt and ERK pathways in a human hepatoma cell line (HepG2). J Nutr 136: 2715-2721, 2006.

32. Kim EJ, Choi CH, Park JY, Kang SK and Kim YK: Underlying mechanism of quercetin-induced cell death in human glioma cells. Neurochem Res 33: 971-979, 2008.

33. Zhang L, Chen W and Li X: A novel anticancer effect of butein: inhibition of invasion through the ERK $1 / 2$ and NF-kappa B signaling pathways in bladder cancer cells. FEBS Lett 582: 1821-1828, 2008.

34. Lee SH, Seo GS, Jin XY, Ko G and Sohn DH: Butein blocks tumor necrosis factor alpha-induced interleukin 8 and matrix metalloproteinase 7 production by inhibiting p38 kinase and osteopontin mediated signaling events in HT-29 cells. Life Sci 81: 1535-1543, 2007.

35. Cory S and Adams JM: The Bcl 2 family: regulators of the cellular life-or-death switch. Nat Rev Cancer 2: 647-656, 2002.

36. Kim NY, Pae HO, Oh GS, et al: Butein, a plant polyphenol, induces apoptosis concomitant with increased caspase-3 activity, decreased Bcl-2 expression and increased Bax expression in HL-60 cells. Pharmacol Toxicol 88: 261-266, 2001.

37. Bechtel W and Bauer G: Modulation of intercellular ROS signaling of human tumor cells. Anticancer Res 29: 4559-4570, 2009. 
38. Victor VM, Rocha M, Sola E, Banuls C, Garcia-Malpartida K and Hernandez-Mijares A: Oxidative stress, endothelial dysfunction and atherosclerosis. Curr Pharm Des 15: 2988-3002, 2009.

39. Shukla S and Gupta S: Apigenin-induced prostate cancer cell death is initiated by reactive oxygen species and p53 activation. Free Radic Biol Med 44: 1833-1845, 2008.

40. Nakazato T, Ito K, Ikeda Y and Kizaki M: Green tea component, catechin, induces apoptosis of human malignant B cells via production of reactive oxygen species. Clin Cancer Res 11: 6040-6049, 2005.

41. Sharma V, Joseph C, Ghosh S, Agarwal A, Mishra MK and Sen E: Kaempferol induces apoptosis in glioblastoma cells through oxidative stress. Mol Cancer Ther 6: 2544-2553, 2007.
42. Moon DO, Kim MO, Choi YH, Hyun JW, Chang WY and Kim GY: Butein induces G(2)/M phase arrest and apoptosis in human hepatoma cancer cells through ROS generation. Cancer Lett 288: 204-213, 2010.

43. Chen YH, Yeh CW, Lo HC, Su SL, Hseu YC and Hsu LS Generation of reactive oxygen species mediates butein-induced apoptosis in neuroblastoma cells. Oncol Rep 27: 1233-1237, 2012. 